\title{
MATHEMATICAL SIMULATION OF THE SLAG CONTAMINATION IN A CONTINUOS CASTING TUNDISH*
}

\author{
Saul Garcia Hernandez ${ }^{1}$ \\ Jose de Jesus Barreto² \\ Rodolfo Davila Morales ${ }^{3}$ \\ Ismael Calderon Ramos ${ }^{4}$ \\ Enif Gutierrez \\ Francisco Andres Zepeda Díaz ${ }^{6}$ \\ Beatriz Adriana Martinez Lara ${ }^{7}$
}

\begin{abstract}
The research work objective is to study a new ladle shroud internal design to reduce the slag emulsification in the tundish during ladle transient periods. A 3D mathematical model of the tundish was created to solve the fundamental equations, a turbulence model, and a multiphase model. The results show that using a conventional ladle shroud, the fluid is delivered with an excessive amount of kinetic energy being dissipated inside the tundish bath, generating strong mixing flow patterns and entrapping a massive amount of slag. In the other hand, the proposed ladle shroud dissipates the kinetic energy before the fluid enters the tundish promoting less intense mixing patterns; thus, the amount of slag emulsification is reduced significantly. Consequently, if the internal design of the ladle shroud is able to dissipate the kinetic energy before the fluid enters the tundish, it shall be possible to reduce considerable the slag emulsification and the slag opening area.
\end{abstract}

Keywords: Mathematical simulation; Slag contamination; Tundish.

1 Ph.D., Professor, Metallurgy Graduate Center, TecNM-Instituto Tecnológico de Morelia,Morelia, Michoacan, Mexico.

2 Ph.D., Professor, Metallurgy Graduate Center, TecNM-Instituto Tecnológico de Morelia,Morelia, Michoacan, Mexico.

3 Ph.D., Professor, Department of Metallurgy and Materials Engineering, Instituto Politecnico Nacional-ESIQIE, Mexico, Mexico City, Mexico.

4 Ph.D., Professor, Department of Engineering of Materials, Universidad Autónoma de Coahuila Facultad de Ingeniería Mecánica y Eléctrica, Monclova, Coahuila, Mexico.

5 Ph.D., Professor, Metallurgy Graduate Center, TecNM-Instituto Tecnológico de Morelia,Morelia, Michoacan, Mexico.

6 Ing., Student, Metallurgy Graduate Center, TecNM-Instituto Tecnológico de Morelia,Morelia, Michoacan, Mexico.

7 M. Sc., Professor, Department of Biochemical Engineering, TecNM-Instituto Tecnológico de Morelia,Morelia, Michoacan, Mexico. 


\section{INTRODUCTION}

The study of the tundish slag contamination emerge from the need of remove macro inclusion generated during the ladle change operation [1] and which are detected in the final product affecting the steel mechanical properties. Takahashi [2] and Martin [3] indicate that the amount of this inclusion increases during the ladle change operation due to the slag emulsification phenomenon, which can have different origin as indicated by Ferro [4], such the thickness of the slag layer and the tundish steel turbulence. This last, according with Kelvin and Helmholtz [5], induces surface instabilities forming level waves able to drag small slag drops into the bath forming an emulsion. At the same time, the amount of entrapped slag is also strongly affected by its physical properties since Sovolainen [6] and Sulasalmi [7] indicate that the critical velocity to induce the emulsification phenomenon change as a function of the viscosities, densities, and surface tension of both phases. According with Ooi et al. [8], the interfacial tension could change by chemical reactions taking place into the fluids interface, which will decrease the values of this variable as indicated Chung and Cramb [9]. Since the physical properties of the steel and slag are frequently taken as constant, there is the need of search for other ways to try to reduce or control the emulsification phenomenon. Other authors have try to control this detrimental phenomenon by employing flow control devices, such Aiub [10] which used turbulent inhibitors to reduce this problem. Following this tendency, Canale [11] advices that to reduce the emulsification phenomenon, a better control of the energy contained into the tundish fluid must be achieved. To achieve this, in a first try to reduce the energy contained in the steel before it enters into the tundish, Solorio [12] changes the internal ladle shroud design using cylindrical chambers, nevertheless this changes indices inclusion entrapment at the ladle entry. In a second work, Solorio [13] change the cylindrical chambers for rhombus chambers obtaining a reduction of the kinetic energy into the steel delivered by the ladle shroud without the problem of inclusion entrapment at the ladle entry. This new design was studied by Morales et al. [14] by physical modeling during steady state conditions finding that this design produces an increment in the mixed flow reducing the dead and plug flows. Consequently, as this new ladle shroud design has shown considerable benefits to control the fluid flow patterns inside the tundish during steady state conditions, the objective of the present work is to study this new ladle shroud design to assist in the reduction of slag contamination and slag opening area in the tundish during transient periods considering a bare tundish.

\section{MATERIAL AND METHODS}

A three dimensional mathematical model was developed considering the NavierStokes equations, the standard k- $\varepsilon$ model, and the Volume of Fluid model.

\subsection{Fundamental Equations}

The time-dependent transport equations for mass and momentum are expressed as follow $[15,16]$ :

$$
\begin{gathered}
\frac{\partial u_{i}}{\partial x_{i}}=0 \\
\rho \frac{\partial u_{i}}{\partial t}+\rho \frac{\partial\left(u_{i} u_{j}\right)}{\partial x_{i}}=-\frac{\partial P}{\partial x_{i}}+\frac{\partial}{\partial x}\left[\mu_{e f f}\left(\frac{\partial u_{i}}{\partial x_{j}}+\frac{\partial u_{j}}{\partial x_{i}}\right)\right]+\rho g_{i}+F_{i}
\end{gathered}
$$




\subsection{The Standard k- $\varepsilon$ Turbulence Model}

The standard k- $\varepsilon$ model of Launder and Spalding [17] was selected to model the turbulence. The equations for turbulent energy $k$ and dissipation rate $\varepsilon$ are given by:

$$
\begin{gathered}
\rho \frac{\partial}{\partial t}(k)+\rho \frac{\partial k u_{i}}{\partial x_{i}}=\frac{\partial}{\partial x_{j}}\left[\left(\mu+\frac{\mu_{t}}{\sigma_{k}}\right) \frac{\partial k}{\partial x_{j}}\right]+G_{k}-\rho \varepsilon \\
\rho \frac{\partial}{\partial t}(\varepsilon)+\rho \frac{\partial \varepsilon u_{i}}{\partial x_{i}}=\frac{\partial}{\partial x_{j}}\left[\left(\mu+\frac{\mu_{t}}{\sigma_{\varepsilon}}\right) \frac{\partial \varepsilon}{\partial x_{j}}\right]+C_{1 \varepsilon} \frac{\varepsilon}{k} G_{k}-C_{2 \varepsilon} \rho \frac{\varepsilon^{2}}{k}
\end{gathered}
$$

The recommended values of the constant proposed by Lauder and Spalding were: $\mathrm{C} 1=1.44, \mathrm{C} 2=1.92, \sigma_{\varepsilon}=1.3, \sigma_{\mathrm{k}}=1.0, \mathrm{C}_{\mu}=0.09$.

\subsection{Multiphase Model}

The multiphase system composed of immiscible fluids was modelled by solving the Volume of Fluid (VOF) model $[18,19]$. The VOF method is an Eulerian method that uses a volume fraction indicator to determine the location of the interfaces of different phases in all cells of a computational domain.

In order to minimize the effects of the inaccurate interpolation for some physical quantities, the model consider incompressible, immiscible fluids, no phase change between fluids, then the variable density and viscosity present at each cell can be expressed on the base of their fraction as shown below

$$
\begin{array}{r}
\rho_{\text {mix }}=\alpha_{\rho} \rho_{\rho}+\left(1-\alpha_{q}\right) \rho_{\rho} \\
\mu_{\text {mix }}=\alpha_{\rho} \mu_{\rho}+\left(1-\alpha_{q}\right) \mu_{\rho}
\end{array}
$$

The tracking of the interphases between the phases is accomplished by the solution of a continuity equation for the volume fraction. For the qth phase, this equation has the following form:

$$
\frac{1}{\rho_{q}}\left[\frac{\partial}{\partial t}\left(\alpha_{q} \rho_{q}\right)+\nabla \cdot\left(\alpha_{q} \rho_{q} \vec{v}\right)=S_{\alpha_{q}}+\sum_{p=1}^{n}\left(\dot{m}_{p q}-\dot{m}_{q p}\right)\right]
$$

The volume fraction equation will not be solved for the primary phase; the primary phase volume fraction will be computed based on the following constraint:

$$
\sum_{q=1}^{n} \alpha_{q}=1
$$

The volume fraction equation is solved through an explicit time discretization method and the employed reconstruction based scheme was the Geo-Reconstruct.

A single momentum equation is solved throughout the domain, and the resulting velocity field is shared among the phases. The momentum equation, shown below, is dependent on the volume fraction of all phases through properties $\rho$ and $\mu$.

$$
\frac{\partial}{\partial t}\left(\rho_{m i x} \nabla\right)+\nabla \cdot\left(\rho_{m i x} \nabla \nabla\right)=-\nabla p+\nabla\left[\mu_{m i x}(\nabla \vec{v}+\nabla \vec{u})\right]+\rho \vec{g}+S_{\sigma}
$$

The governing equations were discretized using the finite volume technique and solved using the commercial CFD package, considering the computational segregated-iterative method, and the physical properties indicated in Table 1. The non-linear momentum equations were linearized using the implicit approach. The discretization was performed using the First Order Upwind scheme as a first approach. The PRESTO! scheme was used for pressure interpolation 
Table 1. Physical properties

\begin{tabular}{|c|c|c|c|c|}
\hline & $\begin{array}{c}\text { Density } \\
\mathrm{Kg} / \mathrm{m}^{3}\end{array}$ & $\begin{array}{c}\text { Viscosity } \\
\mathrm{g} / \mathrm{m}^{*} \mathrm{~s}\end{array}$ & $\begin{array}{c}\text { Surface tension } \\
\mathrm{N} / \mathrm{m}\end{array}$ & $\begin{array}{c}\text { Interfacial tension } \\
\mathrm{N} / \mathrm{m}\end{array}$ \\
\hline Steel & 7050 & 0.0064 & 1.9 & Steel-Slag $=0.74$ \\
\hline Slag & 2800 & 0.18 & 1.4 & \\
\hline Air & 1.225 & $1.7894 \mathrm{e}-05$ & - & Steel-air $=1.84$ \\
\hline
\end{tabular}

\section{RESULTS AND DISCUSSION}

Using the VOF model a single strand tundish model (Figure 1) was simulated employing the above mathematical model. First, the system was simulated considering a velocity inlet calculated for $4.83 \times 10-4 \mathrm{~m} 3 / \mathrm{s}$ to keep the normal operating level. Once the steady state was reached, the velocity inlet was changed to zero, and the simulation continues until the bath level decreases until the ladle change level. At this point, the velocity inlet was changed to $14.5 \times 10-4 \mathrm{~m} 3 / \mathrm{s}$ and the simulation continues until the normal operating level was reached again. Finally, the velocity inlet was changed again to $4.83 \times 10-4 \mathrm{~m} 3 / \mathrm{s}$ for a small period of time. This procedure is schematized in Figure 2.
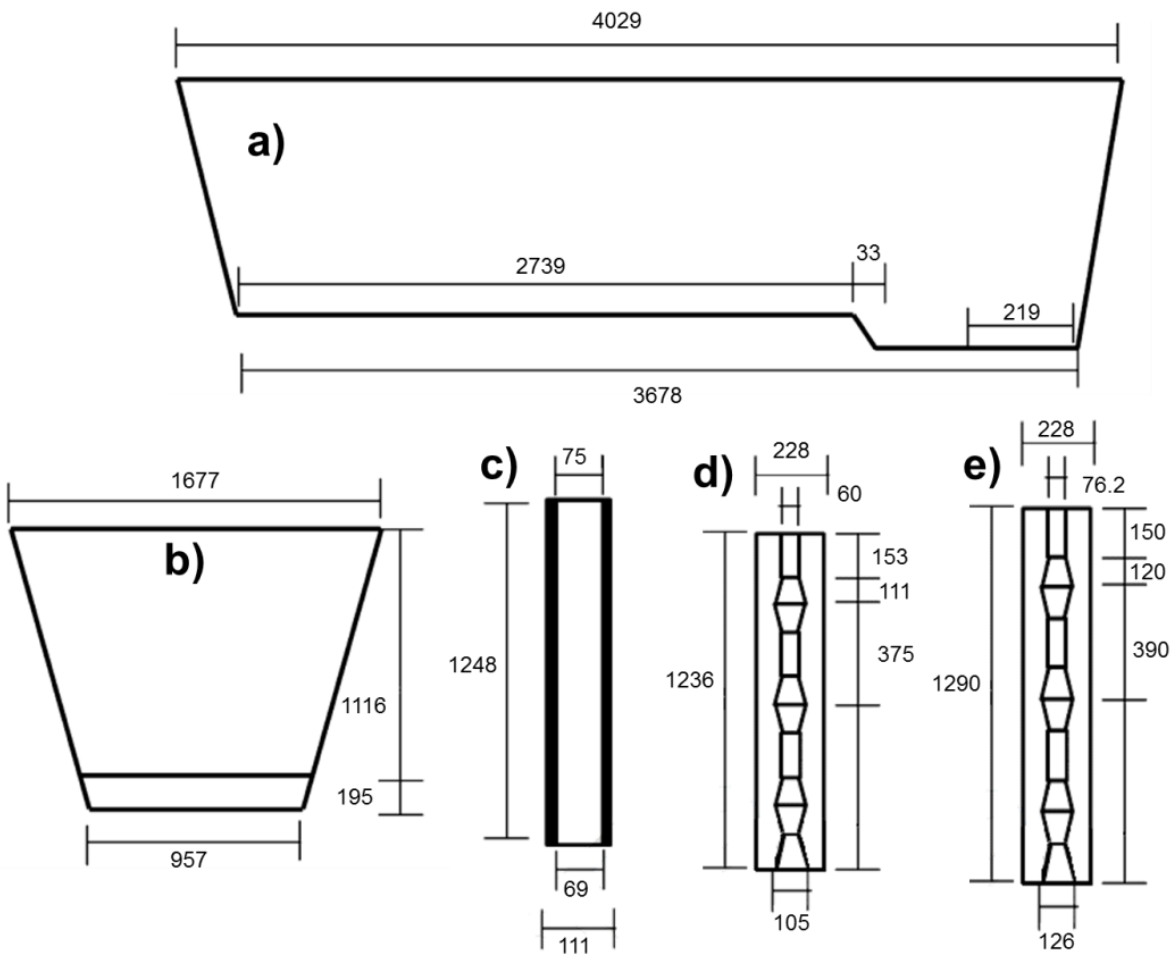

Figure 1. Tundish dimensions (mm), a) Frontal view, b) Lateral view, c) Conventional ladle shroud, d) Dissipative ladle shroud - small, and e) Dissipative ladle shroud - large. 
Previous ladle - Ladle change - New ladle

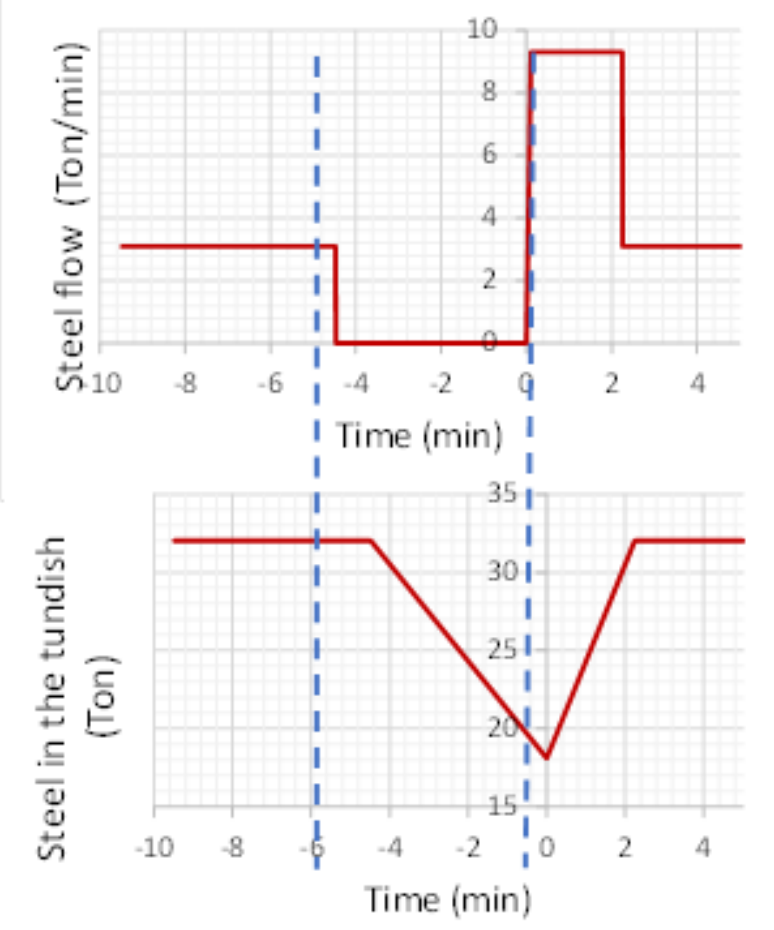

Figure 2. Schematic representation of the ladle change operation during the mathematical modeling.

Figure 3 shows the modelling results of the ladle change operation and the detection of the emulsification contamination for the three ladle shrouds. The figure starts showing a sequence of the modelling images for the $\mathrm{CL}$, which starts dragging a big amount of air into the bath during the first three seconds and it is until the fourth second when the slag starts being dragged into the bath. During this short period of time, the air bubbles move fast from the entry zone to the tundish left side; then, the bubbles change direction abruptly toward the free surface promoting the break-out of the slag layer. At the next ten seconds, the slag contamination is evident in the first half of the tundish and its intensity decreases as the fluid moves toward the outlet. During this period of time, these variations induce strong free surface fluctuations and the slag layer has been opened. The last sequence shows the images after 20 seconds, where the slag contamination is fully developed and the small oil drops have reached the tundish outlet. Comparing these results to those obtained using the new design (DLS-small and DLS-large), it is clear that the amount of dragged air during the first three seconds is a lot lower, the bath level shows a better stability, the slag layer opening is smaller, and the dragged slag is also lower (See Figure 4). Following the previous sequence, the next ten seconds shows clearly that the both DLS reduces considerably the slag emulsification. At the tenth second, at the entry zone, the emulsification is a lot lower than the CLS case. Comparing the last sequence at the same time steps, it was observed that the slag contamination was considerable reduced, the slag opening was also reduced, and the free surface remained very stable. Considering the previous results, it is clear that the fluid flow performance induced by DLS reduces considerable the slag contamination phenomenon, the slag layer opening, and the free surface fluctuation. It is important to notice, that the remaining slag inside the bath at different levels is due to the oil dragged at the start of the emulsification which has not reached the oil layer and keeps moving inside the bath. 


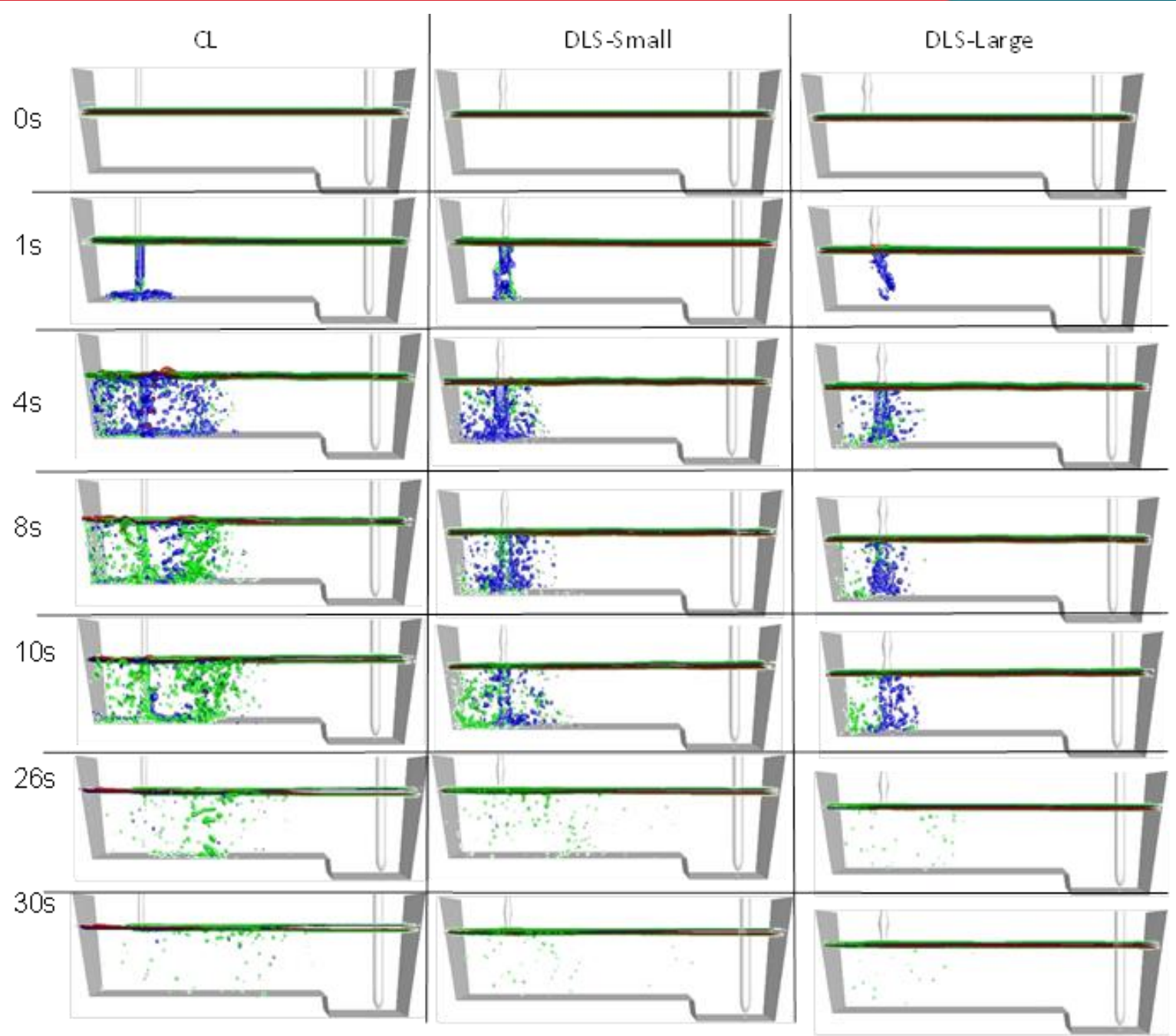

Figure 3. Slag contamination images at different times during the transient period of the modeling, Conventional ladle - first column, Dissipative ladle-small - second column, and Dissipative ladle-large - third column.

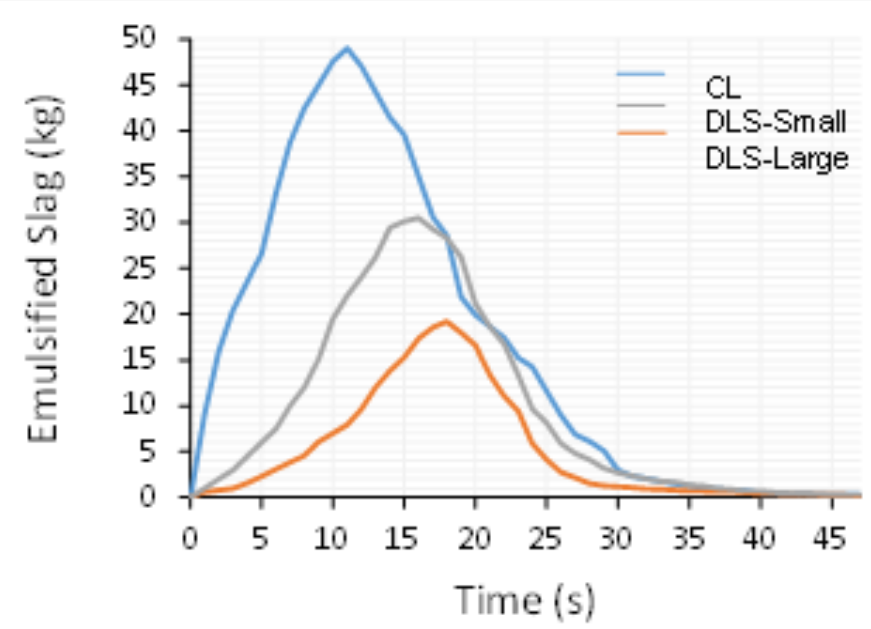

Figure 4. Dragged Slag $(\mathrm{kg})$ during the ladle change operation. 
The slag opening was analyzed by mathematical images (Figure 5), which show that while the slag contamination phenomenon develops, the slag layer opening takes place at the same time. This slag layer opening starts at the moment that the new ladle flow rate is activated, and continues strongly developing while the shroud tip is uncovered and the tundish bath level is low. Nevertheless, the covering layer opening remains so intense even when the liquid cover the shroud tip and the bath level is higher, and it is observed that the slag opening area decreases as the bath level increases but remaining during the whole operation. This is due to an ascending flow from the tundish bottom, close to the lateral walls, which converges at the center of the free surface. These patterns induce the formation of two recirculations close to the ladle shroud, which remain almost at the same zone, changing slightly its position and intensity. These recirculations drag the slag towards the tundish center and the tundish right side; the pulled slag is close enough to the entry jet to be dragged promoting the bath contamination during the whole operation. In the other hand, both DLS clearly show a reduction in the slag opening (Figure 5 and Figure 6); this is because the ascending flow at the lateral walls is now smaller, reducing its movement towards the center of the free surface and consequently reducing the recirculations intensity. As a consequence, the slag is moved with less intensity towards the tundish right side and the bath level center, inducing that as the bath level increases the slag is not dragged and the slag contamination is not promoted any longer.

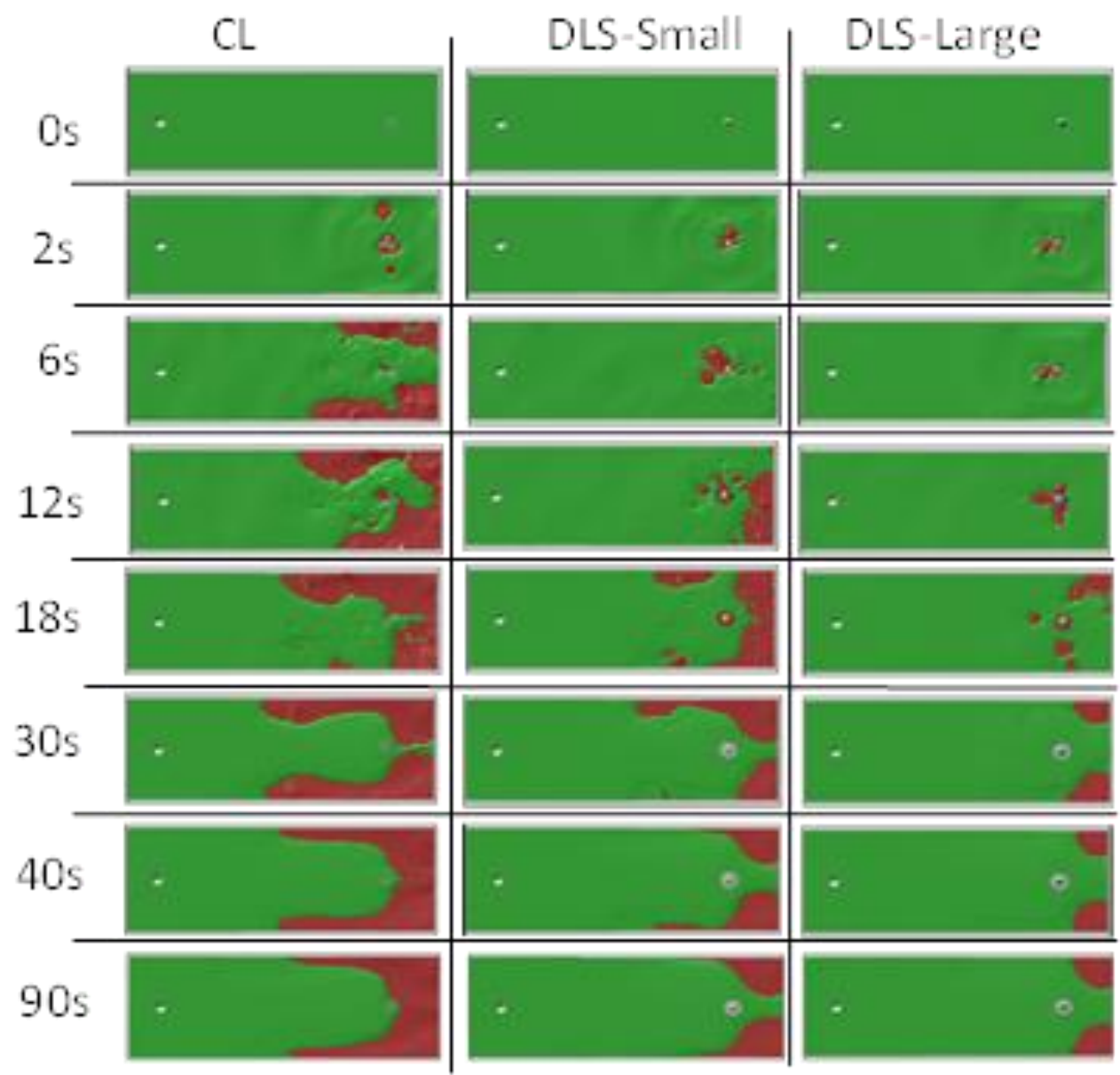

Figure 5. Slag layer opening at different times during the transient period of the modeling, Conventional ladle - first column, Dissipative ladle-small - second column, and Dissipative ladle-large - third column. 


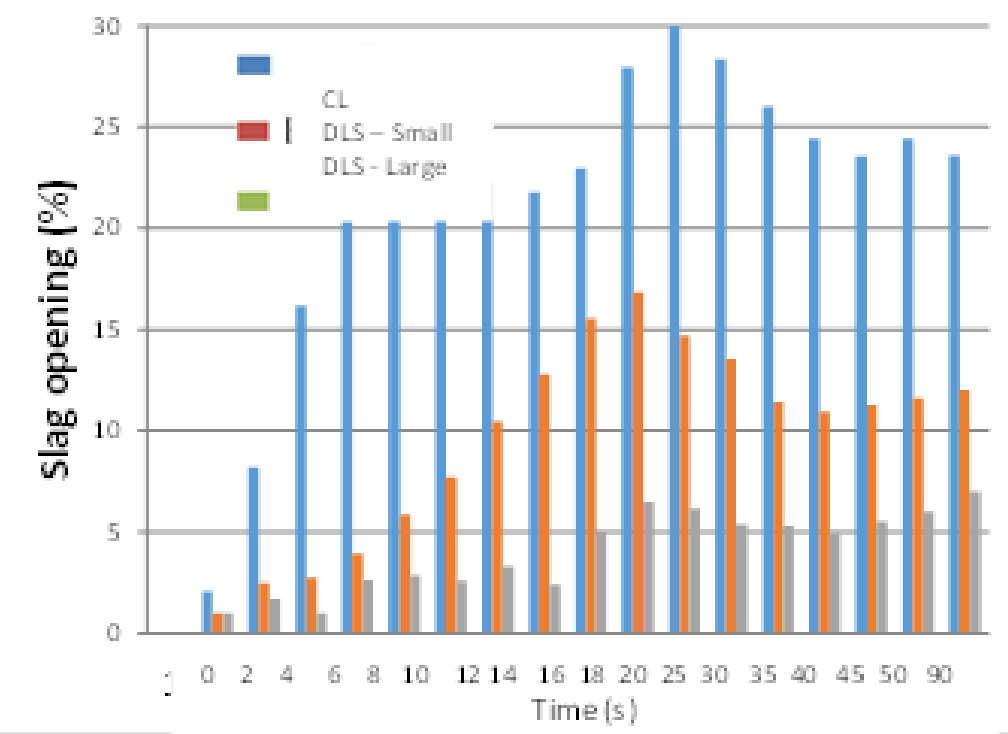

Figure 6. Slag layer opening percentage as function of time.

\section{CONCLUSION}

1) The high turbulent kinetic energy levels contained by the liquid delivered by the ladle shroud are strongly dissipated at the tundish entry zone inducing the air and slag dragging into the bath, forming the immiscible multiphase emulsion.

2) The conventional ladle shroud in a bare tundish induces vortexes formation at the bath level next to the entry zone. These vortexes promote continuous slag dragging into the bath causing the emulsification phenomenon during the transition period.

3) The dissipative ladle shroud improves the flow patterns delivering a fluid with less turbulent kinetic energy, reducing the amount of slag and air dragged into the bath during the whole operation.

4) The dissipative ladle shroud significantly reduces the slag opening area since it delivers a less turbulent fluid.

5) A better control of the fluid flow patterns inside the tundish can be achieved by modifying the ladle shroud internal geometry design reducing the need of fluid flow control devices.

\section{Acknowledgments}

The authors gratefully acknowledge the National Council of Science and Technology, Mexico and the institutions IPN-ESIQIE, TecNM-ITM, SNI, PRODEP for all support given to carry out this work.

\section{REFERENCES}

1 Clyde B. Impurities in ingineering materials. $1^{\underline{a}}$ ed. New York: Marcel-Dekker; 2000.

2 Takahashi K, Ando M, Ishii T. Numerical investigation of unsteady molten steel flow and inclusion behavior in the tundish in the ladle change period. ISIJ Int. 2014; 54(2): 304310.

3 A. Martín, Estudio del origen de inclusiones en el repartidor de colada continua de ternium siderar, Industrial report. 2012: 265-270.

4 L. Ferro, "Steel Cleanliness in Continuous Cating Slabs Ternium sederar" Industrial report. 1996: 45-48. 
5 Sharan A, Cramb AW. Interfacial tensions of liquid Fe-Ni alloys and stainless steels in contact with $\mathrm{CaO}-\mathrm{SiO} 2 " \mathrm{Al} 2 \mathrm{O} 3-$ based slags at $1550{ }^{\circ} \mathrm{C}$. Metall Mater Trans B. 1995; 26(1): 87-94.

6 Savolainen J, Fabritius T, Mattila O. Effect of Fluid Physical Properties on the Emulsification. ISIJ Int. 2009; 49(1): 29-36.

7 Sulasalmi P, Kärnä A, Fabritius T, Savolainen J. CFD Model for Emulsification of Slag into the Steel. ISIJ Int. 2009; 49(11): 1661-1667.

8 Ooi H, Nozaki T, Yoshii Y. The Effect of Chemical Iron Reactions and on the Interfacial Slag Tension between Molten. Tetsu-to-Hagané. 1972; 58: 12-23.

9 Chung Y, Cramb AW. Dynamic and equilibrium interfacial phenomena in liquid SteelSlag systems. Metall Mater Trans. 2000; 31(5): 957-971.

10 Aiub M, Galant M. Effects of turbulence inhibitors on slag emulsification in the continuous casting tundish, steelmaing conference, Rosario Argentina, 2001.

11 Canale LCF, Mesquita RA, Totten GE. Failure analysis of heat treated Steel components. 1를 ed. The United States of America: ASM international; 2008.

12 Solorio G, Morales RD, Palafox J, Ramos A. Modeling the Effects of a Swirling Flow on Temperature Stratification of Liquid Steel and Flotation of Inclusions in a Tundish. ISIJ Int. 2005; 45(8): 1129-1137.

13 Solorio G, Davila R, Barreto JJ. Vergara HJ, Ramos A, Galvan SR. Numerical Modelling of Dissipation Phenomena in a New Ladle Shroud for Fluidynamic Control and Its Effect on Inclusions Removal in a Slab Tundish. Steel Res Int. 2013; 84: 863-875.

14 Morales K, Guthrie R, Isac M., Morales R. D. Ladle shroud as a flow control device for tundish operations. Metallurgical and Materials Transactions B. 2013; 44(1): 63-79

15 Poirier DR, Geiger GH. Transport Phenomena in Materials Processing, Ed. TMS, Warrendale PA, USA, 1994: 39.

16 Fluent Guides, Fluent Inc., Lebanon NH, USA, 2007.

17 Launder BE, Spalding DB. The numerical computation of turbulent flow. Comp. Meth, in Appl. Mech, and Eng.,3, 1974 (2): 269-289.

18 Hirt CW, Nichols BD. Volumen of fluid (VOF) Method for the Dynamics of Free Boundaries. J. Comp. Physics, 1981 (39): 201-225.

19 Liovic P, Liow JL, Rudman M. A Volume of Fluid (VOF) Method for the Simulation of Metallurgical Flows. ISIJ Int., 2001 (41): 225-233. 